\title{
Affected Cerebrovascular Territories in Presumed Cardioembolic Stroke in Patients With Left Atrial or Ventricular Thrombus
}

\author{
Jodi A. Dodds, MD; Amish Parikh, BS \\ Department of Neurology, Duke University Hospital, Durham NC, United States of America
}

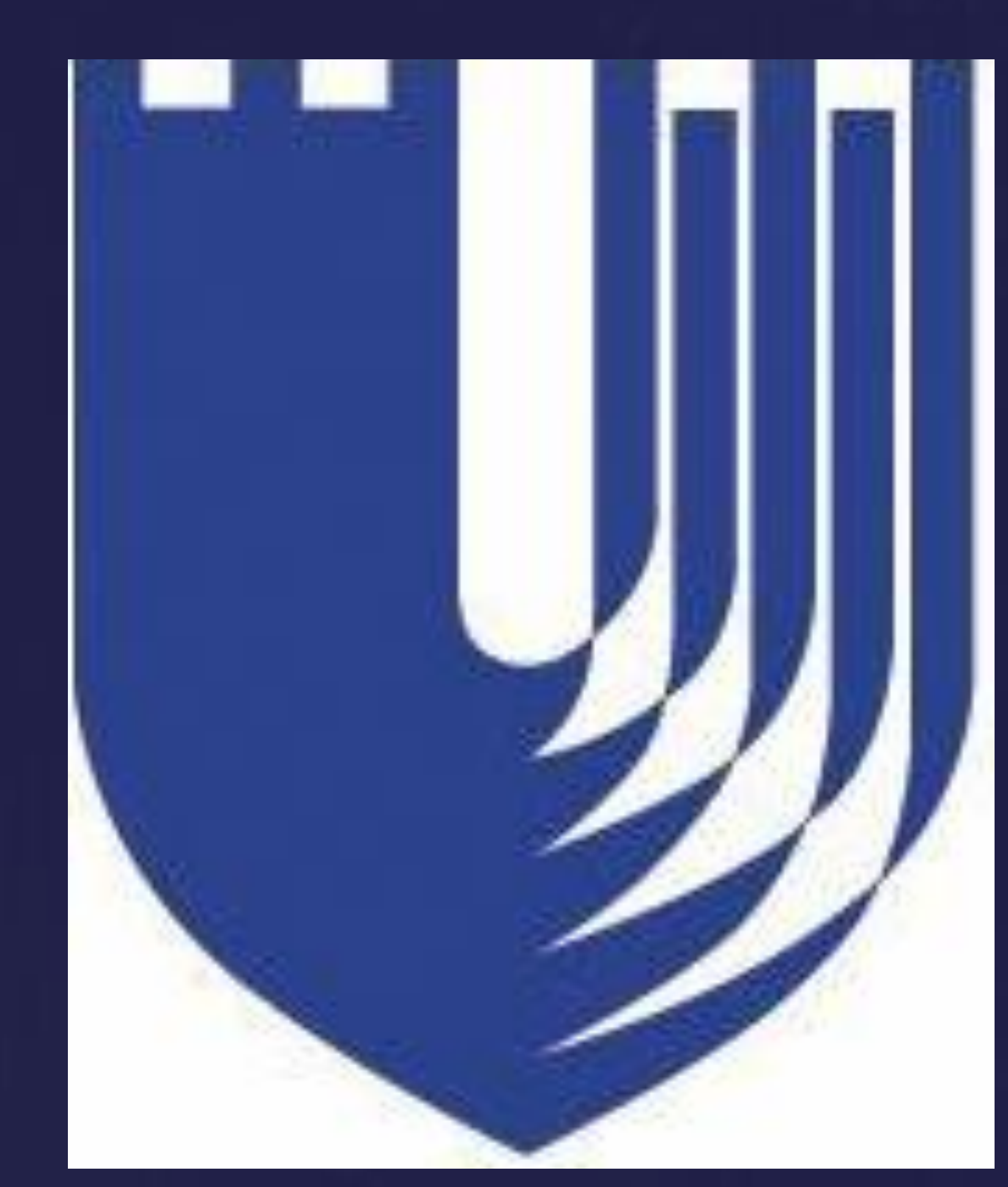

\section{BACKGROUND:}

In the process of evaluating patients with acute ischemic stroke lacking a clear etiology at presentation ("cryptogenic stroke"), echocardiography is a common diagnostic tool used in attempting to define the origin of a suspectec thromboembolic event. To date, no study has been published identifying which cerebrovascular territories are affected ir patients with acute ischemic stroke who are identified as having either left atria or left ventricular thrombus on cardiac imaging

\section{OBJECTIVE:}

The aim of this analysis was to identify cerebrovascular distributions of infarctions in high-probability cardioembolic strokes in patients with left atrial or ventricular thrombi.

\section{METHODS:}

This was a retrospective cohort study utilizing an academic institutional database to identify patients with diagnosis codes for acute ischemic stroke. Patient records were then filterec by CPT codes in order to select patients who underwent transthoracic 0 transesophageal echocardiography cardiac CT, and/or cardiac MRI. Further filters were applied to identify the subset of patients on therapeutic anticoagulation. Patients lacking a definitive left atrial or ventricular thrombi on cardiac imaging were further excluded, as well as patients who intracardiac thrombus was identified $>14$ days before or after presenting with acute ischemic stroke. Patients in whom cardiac imaging studies were inconclusive for the presence of ar intracardiac thrombus were alsc excluded in order to ensure that potential intracardiac thrombus mimics were not analyzed.

A vascular neurologist then reviewed the brain magnetic resonance image (MRI) or head computed tomography (CT) images of patients meeting al inclusion criteria, and classified the cerebrovascular territories for each acute infarction identified. Territories included middle cerebral artery (MCA) anterior cerebral artery (ACA), posterior cerebral artery (PCA), superior cerebellar artery (SCA) anterior inferior cerebellar artery (AICA), posterior inferior cerebella artery (PICA), and basilar artery (not including cerebellar vessels already listed)

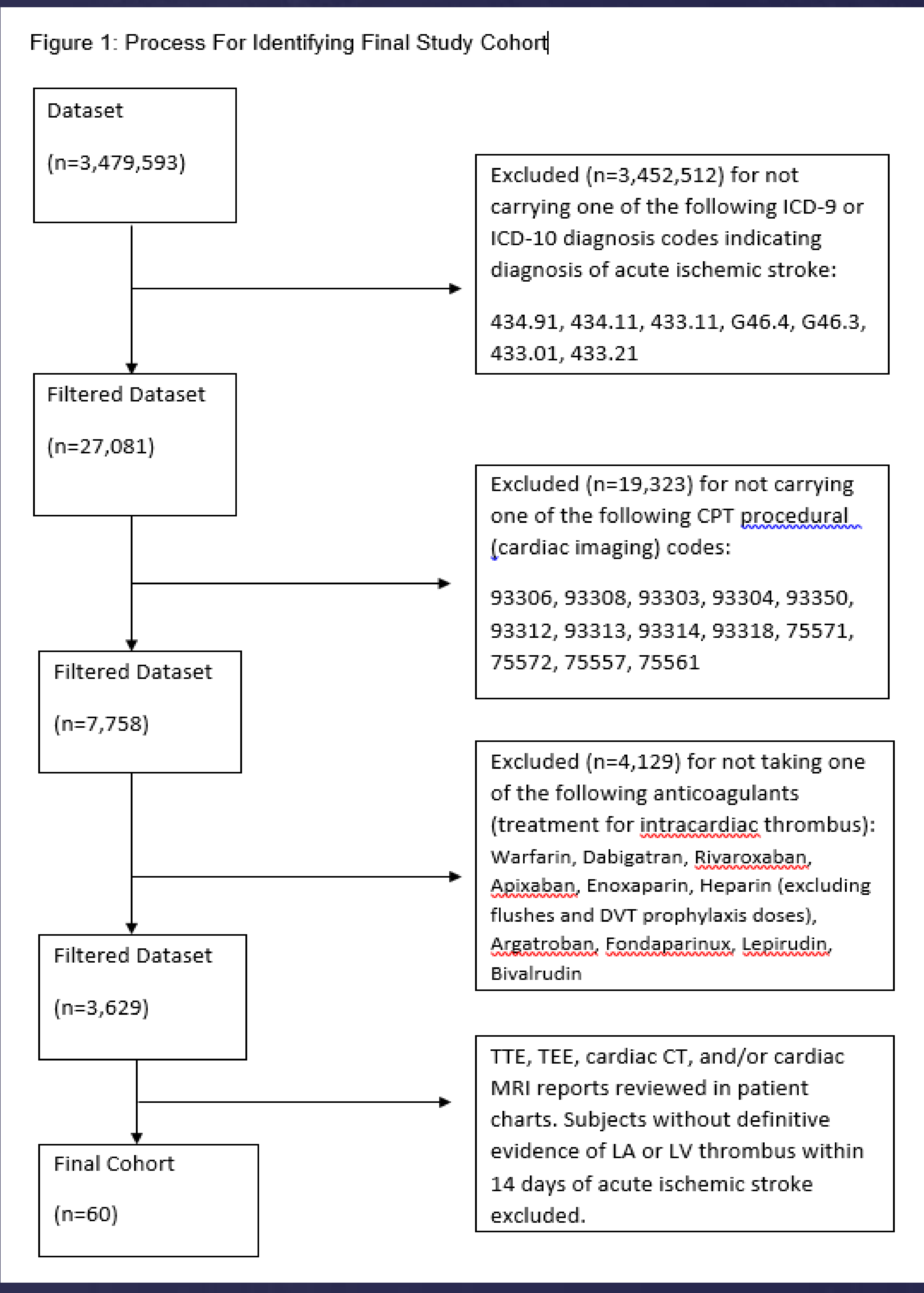

Table 1: Cerebrovascular Territories Affected by Acute Ischemic Stroke in Patients with Left Atrial or Ventricular Thrombi

\begin{tabular}{|l|l|l|l|}
\hline $\begin{array}{l}\text { Cerebrovascular } \\
\text { Territory }\end{array}$ & Right & Left & Midline \\
\hline $\begin{array}{l}\text { Middle Cerebral Artery } \\
\text { (MCA) }\end{array}$ & $21(25 \%)$ & $28(33.3 \%)$ & \\
\hline $\begin{array}{l}\text { Anterior Cerebral } \\
\text { Artery (ACA) }\end{array}$ & $3(3.6 \%)$ & $7(8.3 \%)$ & \\
\hline $\begin{array}{l}\text { Posterior Cerebral } \\
\text { Artery (PCA) }\end{array}$ & $6(7.1 \%)$ & $7(8.3 \%)$ & $2(2.4 \%)$ \\
\hline $\begin{array}{l}\text { Superior Cerebelllar } \\
\text { Artery (SCA) }\end{array}$ & $1(1.2 \%)$ & $0(0 \%)$ & \\
\hline $\begin{array}{l}\text { Anterior Inferior } \\
\text { Cerebellar Artery } \\
\text { (AlCA) }\end{array}$ & $1(1.2 \%)$ & $4(4.8 \%)$ & $1(1.2 \%)$ \\
\hline $\begin{array}{l}\text { Posterior Inferior } \\
\text { Cerebellar Artery } \\
\text { (PICA) }\end{array}$ & $3(3.6 \%)$ & & \\
\hline $\begin{array}{l}\text { Basilar Artery (not } \\
\text { including vessels listed } \\
\text { already) }\end{array}$ & & & \\
\hline
\end{tabular}

"Percentages represented in the table reflect percentages of total acute infarctions identified, rather than percentages of subjects.

\section{RESULTS:}

A total of 60 patients were identified for the cohor outlined in Figure 1, and there were a total of 84 acute ischemic infarctions identified on neuroimaging studies across these 60 individuals. Ten patients had multifocal infarctions affecting multiple vascular territories. Table 1 details the cerebrovascular territories affected.

The left middle cerebral artery territory was most frequently involved (46.7\% of patients), followed by the right middle cerebral artery territory (35\% of patients). Anterior circulation territories were disproportionately affected $(85.7 \%$ of total infarctions). Only one acute infarction (1.2\%) occurred in the basilar artery territory that was unrelated to a cerebellar territory

\section{DISCUSSION:}

Because these patients have known intracardiac thrombi, it is interesting to study the locations of their strokes to ascertain more reliably to which locations intracardiac thrombi embolize. The large majority of our cohort sustained strokes in the anterior circulation territories, with the majority of posterior circulation strokes affecting PCA and cerebellar territories. A patient presenting with an isolated pontine stroke and no obvious singular etiology is unlikely to have had a cardioembolic event.

It is possible that the proportion of patients with posterior circulation strokes in the setting of intracardiac thrombi is actually higher than what our study identified, but that these infarcts may be less likely to result in symptoms leading to a clinical presentation. While it is widely recognized that paralysis on one side is concerning for a stroke, as would be seen in a middle cerebral artery territory stroke, patients with limited vertigo and imbalance due to a cerebellar infarction may not recognize these symptoms as concerning for stroke.

\section{LIMITATIONS:}

Retrospective data lends itself to bias

Diagnosis code use for identifying patients and stroke risk factors may result in skewed prevalence of comorbidities

Relatively small sample size, although sizeable enough to make observations about a previously unstudied population

\section{CONCLUSION:}

Acute ischemic cerebral infarctions in patients found to have left atrial or ventricular thrombi on cardiac imaging were most likely to be present in the anterior cerebral circulation territories. The most common location was in the distribution of the left middle cerebral artery.

Acute cerebral infarctions of unclear etiology occurring in the anterior circulation territories warrant cardiac imaging to identify a potential cardioembolic source. 